ORIGINAL ARTICLE

\title{
Community paediatricians' counseling patterns and knowledge of recommendations relating to child restraint use in motor vehicles
}

\author{
J Rothenstein, A Howard, P Parkin, A Khambalia, C Macarthur
}

Injury Prevention 2004;10:103-106. doi: 10.1136/ip.2003.004168

See end of article for authors' affiliations

Correspondence to:

Dr Colin C Macarthur Division of Paediatric

Medicine, Hospital for Sick

Children, 555 University

Avenue, Toronto, Ontario

M5G 1X8, Canada;

colin.macarthur@

sickkids.ca
Background: Road traffic injury is the leading cause of death among Canadian children and youth. Transport Canada recommends four types of child restraint depending on the size of the child, and recent studies have demonstrated the effectiveness of recommended restraint use.

Objectives: To determine community paediatricians' knowledge of Transport Canada recommendations for child restraint use in vehicles, and to examine paediatricians' counseling patterns in relation to child passenger safety.

Methods: A mailed questionnaire survey of all community paediatricians affiliated with the Hospital for Sick Children, Toronto was conducted. A 16 item questionnaire gathered information on knowledge of Transport Canada recommendations for child restraint use, general counseling patterns in relation to child passenger safety, and demographic information.

Results: In total, 60 community paediatricians in active practice were identified. Of these, 48 (80\%) responded to the mailed questionnaire. Almost all paediatricians (92\%) correctly identified the recommended weight for transition to a forward-facing car seat, whereas fewer paediatricians (63\%) correctly identified the recommended weight for transition to a booster seat from a forward-facing car seat, and only one third of paediatricians correctly identified the recommended weight for transition from a booster seat to a seat belt.

Conclusion: Community paediatricians' knowledge of Transport Canada recommendations for child restraint use in vehicles is incomplete. There is a need for such recommendations to be better disseminated to paediatricians and parents so that information on child restraint use is delivered in a clear and consistent manner.
$\mathrm{R}$ oad traffic injury is the leading cause of death among Canadian children and youth. For example, motor vehicle traffic crashes were responsible for 110 deaths in children 0-9 years of age, and for 39\% of all unintentional injury deaths in this age group in $1997 .{ }^{1}$ In Canada and the United States, the mortality rate for motor vehicle traffic crashes among children 0-9 years of age is 3/100 000/year. ${ }^{12}$

Provincial legislation in Ontario Canada requires that drivers wear a seat belt and ensure that passengers under 16 years are buckled up or secured in a child safety seat. Penalties for non-compliance include fines $(\$ 90-\$ 500$ Canadian) and two demerit points. For infants under $9 \mathrm{~kg}$ $(20 \mathrm{lb})$, the law stipulates a rear-facing car seat, whereas for toddlers from $9-18 \mathrm{~kg}(20-40 \mathrm{lb})$, a forward-facing car seat is the law. For children over $18 \mathrm{~kg}(40 \mathrm{lb})$, the law states that such children "can be placed in a booster seat or seat belt".

Transport Canada recommends four types of child restraint depending on the size of the child. ${ }^{3}$ For infants up to $10 \mathrm{~kg}$ (22 lb; approximately 1 year), a rear-facing infant carrier is recommended. A forward-facing child safety seat is recommended for toddlers weighing from $10-18 / 22 \mathrm{~kg}$ (22-40/ $48 \mathrm{lb}$; approximately $1-4.5$ years) depending on the seat model. For children weighing from 18/22-27 kg (40/48-60 lb; approximately $4.5-8$ years) a booster seat is recommended. Larger children should sit in the rear seat and use a lap and shoulder belt restraint.

Recent studies have demonstrated the "real world" effectiveness of recommended restraint use in children. ${ }^{45}$ For example, the risk of significant injury in children 2-5 years of age involved in a motor vehicle crash is 3.5 times greater for children in seat belts, compared with children in child restraint systems. ${ }^{4}$ In addition, the odds of injury for children 4-7 years of age involved in a motor vehicle crash is $59 \%$ lower for children in booster seats, compared with children in seat belts. ${ }^{5}$ Survey data, however, suggest that children graduate "prematurely" to seat belt use. For example, an observational survey in four states in the United States in 1995 showed that $21 \%$ of toddlers (20$40 \mathrm{lb}$ ) and $75 \%$ of preschoolers (40-60 lb) were restrained by seat belt only. ${ }^{6}$

The objectives of this study were to determine community paediatricians' knowledge of Transport Canada recommendations for child restraint use in vehicles, and to examine paediatricians' counseling patterns in relation to child passenger safety.

\section{METHODS}

A mailed questionnaire survey of all community paediatricians affiliated with the Division of Paediatric Medicine at the Hospital for Sick Children, Toronto was conducted. (Approximately $50 \%$ of all primary care paediatricians in Toronto are affiliated with the Division). The mailing address for each paediatrician was obtained from a computerized administrative database. Physicians were excluded if they were no longer in active practice.

A 16 item questionnaire was developed based on the principles of Dillman's total design method. ${ }^{7}$ The questionnaire was pilot tested on staff at the Hospital for Sick Children, revised to increase readability and comprehensibility, then mailed to the office address of each community paediatrician. Repeat mailings of the questionnaire were sent 
to all paediatricians at three and seven weeks after the initial mailing. ${ }^{7}$

The questionnaire gathered information on community paediatricians' knowledge of Transport Canada recommendations for child restraint use in vehicles, their general counseling patterns in relation to child passenger safety, and demographic information. For example, paediatricians were asked to report at what age and weight they recommended that parents move their infant/child: from a rear-facing to a forward-facing car safety seat; from a forward-facing car safety seat to a booster seat; and from a booster seat to a lap and shoulder seat belt. In addition, "in the context of counseling parents", paediatricians were asked to report the frequency with which they asked at the first well child visit whether a rear-facing car safety seat was used for the infant, if they educated parents about securing the harness of child safety seats snugly around the child, if they instructed parents to graduate children from forward-facing car safety seats to booster seats, if they educated parents about the risks to children associated with premature graduation to lap and shoulder seat belts, and if they advised parents that the rear vehicle seat was the safest place for children. Potential responses to the general counseling questions were "never", "some of the time", "most of the time", and "always". In addition, paediatricians were asked to indicate their primary source of information about child passenger safety, what resources on child passenger safety they offered to families, and whether they had treated a child involved in a motor vehicle collision in the past two years. Demographic data gathered included sex and number of years in practice. Responses to the questionnaire items were quantified using proportions and $95 \%$ confidence intervals.

\section{RESULTS}

A total of 60 affiliated community paediatricians in active practice were identified. Of these, $48(80 \%)$ responded to the mailed questionnaire. The median number of years in practice for respondents was 20 years (range 9-36 years), and two thirds were male. There were no differences between respondents and non-respondents on baseline characteristics.

The majority of paediatricians $(63 \%)$ had treated a child involved in a motor vehicle collision in the previous two years. For $38 \%$ of paediatricians, information provided by provincial (Ontario Ministry of Health) and national (Transport Canada) agencies was their primary source of information on child passenger safety. Practice guidelines developed by lead paediatric organizations, for example, the Canadian Paediatric Society and the American Academy of Paediatrics were also cited as important sources of information by $17 \%$. Other sources of information on child passenger safety for paediatricians included published articles in medical journals (17\%) and in the media (17\%). The most common resource on child passenger safety offered to parents was an educational pamphlet (42\%), however, many paediatricians $(46 \%)$ did not offer any resources on child passenger safety to parents.

Community paediatricians' counseling patterns in relation to child passenger safety are described in table 1. Combining the responses "most of the time" and "always", the majority of paediatricians (69\%) advised parents that the rear vehicle seat was the safest place for children. In addition, just over half of all paediatricians (55\%) instructed parents to graduate children from forward-facing car seats to booster seats, rather than seat belts. Fewer paediatricians, however, asked at the first well-child visit if a rear-facing car seat was used (31\%); educated parents to secure the car seat harness securely (29\%); or educated parents about the risks associated with premature graduation to seat belts $(36 \%)$.

Table 2 describes community paediatricians' knowledge of Transport Canada recommendations for child restraint use in vehicles. Almost all paediatricians (92\%) correctly identified the recommended weight for transition to a forward-facing car seat. Only $46 \%$ of paediatricians, however, correctly identified the recommended age. Furthermore, 19\% of all paediatricians suggested that children under 1 year could move from a rear-facing to forward-facing car seat, and one third did not identify an age for transition. In total, $63 \%$ of all paediatricians correctly identified the recommended weight for transition to a booster seat from a forward-facing car seat, whereas, only $21 \%$ correctly identified the recommended age. (Over half of all paediatricians did not identify an age for transition to a booster seat.) In addition, approximately one fifth of paediatricians suggested that children under 4.5 years and children weighing less than $40 \mathrm{lb}$ could move from a forward-facing car seat to a booster seat. One third of paediatricians correctly identified the recommended weight for transition from a booster seat to a seat belt, one third recommended a weight under $60 \mathrm{lb}$, and one third did not identify a recommended weight. One quarter of paediatricians correctly identified the recommended age for transition from a booster seat to a seat belt, whereas, 31\% recommended that children under eight years could move from a booster seat to a seat belt, and $44 \%$ did not identify a recommended age for transition.

\section{DISCUSSION}

The results of this survey suggest that child passenger safety is not a routine component of preventive counseling for community paediatricians. For example, less than one third of paediatricians asked at the first well-child visit if a rearfacing car seat was used. Furthermore, paediatricians' knowledge of Transport Canada recommendations for child restraint use in vehicles was variable. Most paediatricians based their recommendations on the weight of the child, rather than age. Almost all paediatricians identified the appropriate weight for transition from a rear-facing to a

Table 1 Community paediatricians' counseling patterns in relation to child passenger safety; results are number (\%)

\begin{tabular}{|c|c|c|c|c|}
\hline Item & Never & $\begin{array}{l}\text { Some of the } \\
\text { time }\end{array}$ & $\begin{array}{l}\text { Most of the } \\
\text { time }\end{array}$ & $\begin{array}{l}\text { Always } \\
(\%)\end{array}$ \\
\hline Ask at first well child visit if rear-facing car seat is used? & $12(25)$ & $21(44)$ & $10(21)$ & $5(10)$ \\
\hline Educate parents to secure car seat harness securely? & $17(35)$ & $17(35)$ & $12(25)$ & $2(4)$ \\
\hline $\begin{array}{l}\text { Instruct parents to graduate child from a forward-facing car } \\
\text { seat to a booster seat? }\end{array}$ & $5(10)$ & $17(35)$ & $19(40)$ & 7 (15) \\
\hline $\begin{array}{l}\text { Educate parents about risks associated with premature } \\
\text { graduation to lap and shoulder seat belts? }\end{array}$ & $11(23)$ & $20(42)$ & $10(21)$ & $7(15)$ \\
\hline Advise parents that rear vehicle seat is the safest place? & $2(4)$ & $13(27)$ & $18(38)$ & $15(31)$ \\
\hline
\end{tabular}


Table 2 Community paediatricians' knowledge of Transport Canada recommendations for child restraint use in vehicles; results are number (\%)

\begin{tabular}{llll}
\hline & $\begin{array}{c}\text { Rear-facing seat to } \\
\text { forward-facing seat }\end{array}$ & $\begin{array}{l}\text { Forward-facing seat } \\
\text { to booster seat }\end{array}$ & $\begin{array}{l}\text { Booster seat to lap and } \\
\text { shoulder seat belt }\end{array}$ \\
\hline Age & $22(46)$ & $10(21)$ & $12(25)$ \\
Recommended age & $9(19)$ & $11(23)$ & $15(31)$ \\
Below recommended age & $17(35)$ & $27(56)$ & $21(44)$ \\
No response & $44(92)$ & $30(63)$ & $16(33)$ \\
Weight & $1(2)$ & $10(21)$ & $15(31)$ \\
Recommended weight & $3(6)$ & $8(17)$ & $17(35)$ \\
Below recommended weight & No response & &
\end{tabular}

forward-facing car seat, however, only $63 \%$ and $33 \%$ of paediatricians identified the appropriate weight for transition from a forward-facing car seat to a booster seat, and from a booster seat to a seat belt, respectively.

Strengths of our study include the use of a standardized (and pilot tested) questionnaire, and a high response rate. The survey was restricted, however, to a single urban center, and sampled only community paediatricians affiliated with an academic health sciences center. Therefore, whether the results are generalizable to other community paediatricians, for example, those in rural practice or those involved in managed care in the United States, is unknown.

A 1983 mail survey of paediatricians and family physicians in San Antonio, Texas, showed similar results to our study. For example, only $29 \%$ of physicians in that study asked at the first well-child visit if a car restraint was used; the majority (54\%) never discussed motor vehicle safety with parents; and $26 \%$ did not have car safety literature available for families. ${ }^{8}$

Parents look to their primary care paediatrician to provide guidance on childhood injury prevention. ${ }^{9}$ The average length of a preventive care visit in a paediatrician's office, however, is only 16 minutes. ${ }^{10}$ Therefore, there is little time to address injury prevention in general, or motor vehicle occupant safety in specific. Of note, a consensus study involving 23 injury prevention experts across the United States identified motor vehicle occupant injuries as the most important injury prevention counseling priority for paediatricians. ${ }^{10}$ Furthermore, a systematic review of randomized trials of educational interventions delivered in the clinical setting has shown that education can increase child restraint use in the short term (compared with controls), although this effect diminishes over time. ${ }^{11}$ Trials that used education plus

\section{Key points}

- Child passenger safety is not a routine component of preventive counseling by community paediatricians.

- Community paediatricians' knowledge of Transport Canada recommendations for child restraint use in motor vehicles is incomplete.

- Almost half of all community paediatricians did not provide any resources on child passenger safety to parents.

- Better dissemination of Transport Canada recommendations to community paediatricians is needed. reinforcement or resources (for example, free car seats) were shown to be more effective.

Parental barriers to using booster seats include cost, the need to accommodate other children in the vehicle, and the belief that seat belts provide adequate protection. ${ }^{12}$ Parents are also confused about the appropriate age and weight for transition from a car seat to a booster seat. Of note, another study has shown that child safety seat instruction manuals are consistently written at a level that exceeds the reading abilities of most consumers. ${ }^{13}$

Given the burden of injury associated with motor vehicle crashes, child passenger safety is a leading public health priority. ${ }^{14}$ Non-use or misuse of child restraints is common among children killed or injured in motor vehicle crashes. ${ }^{3-6}$ An important barrier to child restraint use is confusion about the age and weight thresholds for transition through the different child restraint systems. ${ }^{12}$ The findings of our study indicate that paediatricians' knowledge of Transport Canada recommendations for child restraint use in vehicles is incomplete. Therefore, one option to reduce the knowledge gap is for better dissemination of the Transport Canada recommendations to paediatricians. This is an important issue as parents consider paediatricians to be credible advocates for child restraint use. ${ }^{912}$ Dissemination of the Transport Canada recommendations directly to parents via public health programs or community based educational programs are also important. The ultimate goal of all such strategies is to deliver information on child restraint use in a clear and consistent manner.

\section{Authors' affiliations}

J Rothenstein, Faculty of Medicine, University of Toronto A Howard, Division of Orthopaedic Medicine, Hospital for Sick Children, Toronto, and Department of Surgery, University of Toronto P Parkin, A Khambalia, C Macarthur, Division of Paediatric Medicine (Paediatric Outcomes Research Team), Hospital for Sick Children, Toronto, and Department of Paediatrics, University of Toronto

\section{REFERENCES}

1 Health Canada. Canadian injury data: mortality (1997) and hospitalizations (1996-1997). Ottawa, Ontario: Health Protection Branch, Laboratory Center for Disease Control, Health Canada, October, 1999.

2 Anonymous. Motor vehicle occupant fatalities and restraint use among children aged 4-8 years: United States, 1994-1998. MMWR Morb Mortal Wkly Rep 49:135-7.

3 Howard AW. Automobile restraints for children: a review for clinicians. CMA 2002;167:769-73.

4 Winston FK, Durbin DR, Kallan MJ, et al. The danger of premature graduation to seat belts for young children. Pediatrics 2000;105:1179-83.

5 Durbin DR, Elliott MR, Winston FK. Belt-positioning booster seats and reduction in risk of injury among children in vehicle crashes. JAMA 2003;289:2835-40. 
6 Decina LE, Knoebel KY. Child safety seat misuse patterns in four states. Accid Anal Prev 1997;29:125-32.

7 Dillman DA. Handbook of survey research. Orlando, FL: Academic Press, 1983.

8 Faber MM, Hoppe SK, Diehl AK. Physician knowledge and clinical behavior regarding automobile safety for children. Pediatrics 1985;75:248-53.

9 Bass JL, Christoffel KK, Widome M, et al. Childhood injury prevention counseling in primary care settings: a critical review of the literature. Pediatrics 1993;92:544-50.

10 Cohen LR, Runyan CW, Downs SM, et al. Pediatric injury prevention counseling priorities. Pediatrics 1997;99:704-10.
11 DiGuiseppi C, Roberts I. Individual-level injury prevention strategies in the clinical setting. The future of children: unintentional injuries in childhood. Los Altos, CA: David and Lucille Packard Foundation, 2000; 10:53-82.

12 Rivara FP, Bennett E, Crispin B, et al. Booster seats for child passengers: lessons for increasing their use. Inj Prev 2001;7:210-3.

13 Wegner M, Girasek DC. How readable are child safety seat installation instructions? Pediatrics 2003;111:588-91.

14 Winston FK, Durbin DR. Buckle up! Is not enough: enhancing protection of the restrained child. JAMA 1999;281:2070-2.

\section{LACUNAE}

\section{Injury prevention-still a low priority!}

D espite the fact that injuries are the leading cause of death in children, a recent study has found that the level of priority given to injury prevention is alarmingly low. The study explored the level of priority given to injury prevention both at a national level and also within the north west London Borough of Brent. The study involved a literature review and completion of a questionnaire by professionals in health, social care, and voluntary organisations in Brent. Respondents, more than half of whom completed the questionnaires, varied from directors, project coordinators, and clinicians. The study established that the government has clearly identified injuries as a priority, this was evident in the white paper Saving Lives: Our Healthier Nation, in which injury prevention was identified as one of four priority areas alongside cancer, coronary heart disease and stroke, and mental health.

Numerous other documents including the Accidental Injury Task Force Report Preventing Accidental Injury-Priorities for Action have emerged over recent years highlighting the same issue, often providing a clear strategy to tackle the high number of childhood injuries. However, when the questionnaire respondents were asked to name any documents they have come across which mention injury prevention, alarmingly there was no mention of any of these documents. Although the government has identified injury prevention as a priority, questionnaire respondents think the level of priority given to injury prevention both in Brent and at a national level was either very low or low and the majority felt this was not appropriate. Respondents suggested injury prevention is given a low priority due to competition against other demands, lack of resources, and lack of organisational focus. Encouragingly, 70\% of respondents felt injury prevention fell into their remit, although fewer than half had carried out or were currently involved in any injury prevention work. Interventions underway included classroom sessions, talking to parents in health interviews, and risk assessments. Reasons given for not being involved in any injury prevention interventions included a lack of resources, particularly funding, lack of partnership work, and a lack of support for those who are wanting or required to carry out injury prevention work.

Recommendations to raise the level of priority given to injury prevention, which stemmed from this study, include:

- Identify a lead person for injury prevention in Brent.

- Ensure national and local documents are accessible to all.

- Form an injury prevention network at both a regional and local level.

- Develop training courses to raise awareness.

- Encourage partnership working.

- Explore funding streams.

- Try to link new interventions to existing projects/schemes, such as the healthy schools scheme.

This short project was carried out as part of the injury prevention course run by the University of Newcastle and Child Accident Prevention Trust by one of the students, Tracy Walsh, a health promotion specialist at Brent Primary Care Trust, London, UK. We are happy to publish similar student projects that may be of wider interest. The should be sent to Injury Prevention Deputy Editor Michael Hayes at mh@capt.org.uk. 